\title{
Forekomst av muskel- og skjelettlidelser i Norge
}

\author{
Sammendrag \\ Bakgrunn. Muskel- og skjelettlidelser \\ er en av de hyppigste årsakene til bruk \\ av både tradisjonelle og alternative \\ helsetjenester og -tilbud. Formålet \\ med artikkelen er å gi en oversikt over \\ forekomst av disse lidelsene i Norge.
}

Materiale og metode. Artikkelen er basert på en rapport om muskel- og skjelettlidelser fra 2004. Det er i tillegg foretatt ikke-systematiske søk i PubMed for artikler innen feltet som er publisert i årene 2005-09.

Resultater. Muskel- og skjelettplager er svært vanlig i befolkningen. 75-80\% vil i løpet av en måned ha opplevd slike smerter eller plager i en eller annen form. Flere kvinner enn menn rapporterer muskel- og skjelettsmerter, og man ser generelt en økning i forekomst med $ø$ kende alder. En unders $ø$ kelse har vist at bare $11 \%$ av befolkningen har muskel og -skjelettsmerter fra ett område, mens omtrent $40 \%$ rapporterer fem eller flere smerteområder. $\emptyset$ kende antall smerteområder er assosiert med nedsatt funksjon og høyere sykefravær og større uføreytelser. Forekomsten av muskel- og skjelettplager ser ut til å holde seg stabil i befolkningen over tid. Samtidig har disse lidelsenes andel av trygdeytelsene vist en fallende tendens de siste ti årene. Allikevel er muskel- og skjelettlidelsene fortsatt den hyppigste medisinske årsaken til sykefravær og uføreytelser.

Fortolkning. Muskel- og skjelettlidelser er utbredt i befolkningen og fortsatt en viktig årsak til trygdeytelser.

\section{Camilla Ihlebæk}

camilla.ihlebak@umb.no

Forskergruppe for natur, helse og livskvalitet Universitetet for miljø- og biovitenskap 1432 Ås

og

Forskningsenhet for stress,

helse og rehabilitering

Uni helse

Bergen

\section{Søren Brage}

Utredningsseksjonen

Arbeids-og velferdsdirektoratet

\section{Bård Natvig}

Nasjonalt revmatologisk rehabiliterings-

og kompetansesenter

Diakonhjemmet Sykehus

og

Seksjon for sosialmedisin

Avdeling for allmenn- og samfunnsmedisin

Institutt for helse og samfunn

Universitetet i Oslo

\section{Dag Bruusgaard}

Seksjon for sosialmedisin

Avdeling for allmenn- og samfunnsmedisin

Institutt for helse og samfunn

Universitetet i Oslo

Muskel- og skjelettlidelser er en av de hyppigste årsakene til at folk oppsøker både tradisjonelle og alternative helsetjenester og -tilbud (1). I Norge, som i mange andre vesteuropeiske land, er disse lidelsene også de dominerende årsakene til sykefravær, rehabilitering og uførepensjonering.

Muskel- og skjelettlidelser omfatter et bredt spekter av tilstander. I noen tilfeller er etiologien kjent, og smertene og plagene kan helt eller delvis forklares ved kjente sykdommer. Men selv for slike tilstander som f.eks. Bekhterevs sykdom eller artrose, er det stor individuell variasjon i grad av symptomer og type konsekvenser for pasienten når det gjelder smerte, livskvalitet, dagligliv og arbeidsliv (2, 3 ). Ved mange tilfeller av muskel- og skjelettlidelser, finner man ingen sikre fysiologiske eller morfologiske endringer som kan forklare smertene. Likeledes er det i mange tilfeller usikkert hvilken relevans eventuelle objektive funn har for forståelsen av det aktuelle symptombildet. Ved slike tilstander finner man sjelden kun én årsak, men mange individuelle og komplekse årsakssammenhenger. I denne artikkelen tar vi for oss forekomsten av muskel- og skjelettlidelser i Norge.

\section{Materiale og metode}

Artikkelen er delvis basert på en rapport om forekomst av muskel- og skjelettlidelser fra
2004 (4). For årene 2005-09 er det foretatt et ikke-systematisk søk i PubMed med et utvalg artikler basert på forfatternes erfaring innen området. For trygdemessige konsekvenser ble det hentet opplysninger fra NAVs nettsider $(5,6)$. Tilgjengelige tabeller over diagnosefordeling ved sykefraværet i 2 . kvartal 2001-09 og uføreytelser 1998-2006 er gjort om til figurer. «Uføreytelse» omfatter både varig uførepensjon og tidsbegrenset uførestønad.

\section{Muskel- og skjelettplager}

Muskel- og skjelettplager er svært vanlig i den norske befolkningen. $75-80 \%$ vil i løpet av en måned ha opplevd smerter eller plager fra muskel- og skjelettsystemet $i$ en eller annen form (7). Det meste av dette utgjøres av lette plager, som ikke krever behandling og som ikke får noen konsekvenser for dagligliv eller deltakelse $\mathrm{i}$ arbeidslivet. Det er likevel en betydelig andel av befolkningen som har kroniske muskel- og skjelettlidelser. I Helseundersøkelsen i NordTrøndelag (HUNT) fant man en aldersjustert insidens for muskel- og skjelettplager med varighet over to uker siste måned på 7,9\% (8), og $51 \%$ av befolkningen rapporterte muskel- og skjelettplager med varighet $i$ tre måneder eller mer siste år (9). I Helseundersøkelsen i Hordaland (HUSK) rapporterte $38 \%$ av menn og $48 \%$ av kvinner i alderen 40-49 år kroniske smerter og stivhet fra muskel- og skjelettapparatet siste år. De tilsvarende tallene for 70-74 åringer var $41 \%$ og $57 \%$ (10). Flere kvinner enn menn rapporterer muskel- og skjelettsmerter (11), og man ser generelt en økning i forekomsten med økende alder, selv om dette variere noe med ulike lidelser og i ulike studier $(10,12)$. Det er funnet en sterk sammenheng mellom

\section{Hovedbudskap}

- Muskel- og skjelettplager er svært vanlig i befolkningen

- De fleste som rapporterer slike plager, rapporterer smerter fra flere områder

- Sykefravær på dette grunnlaget har vært stabilt de siste årene

- For uføreytelser har antallet nye tilfeller vist både en absolutt og en relativ nedgang, men lite tyder på at dette skyldes en reell nedgang i forekomsten av muskel- og skjelettplager 


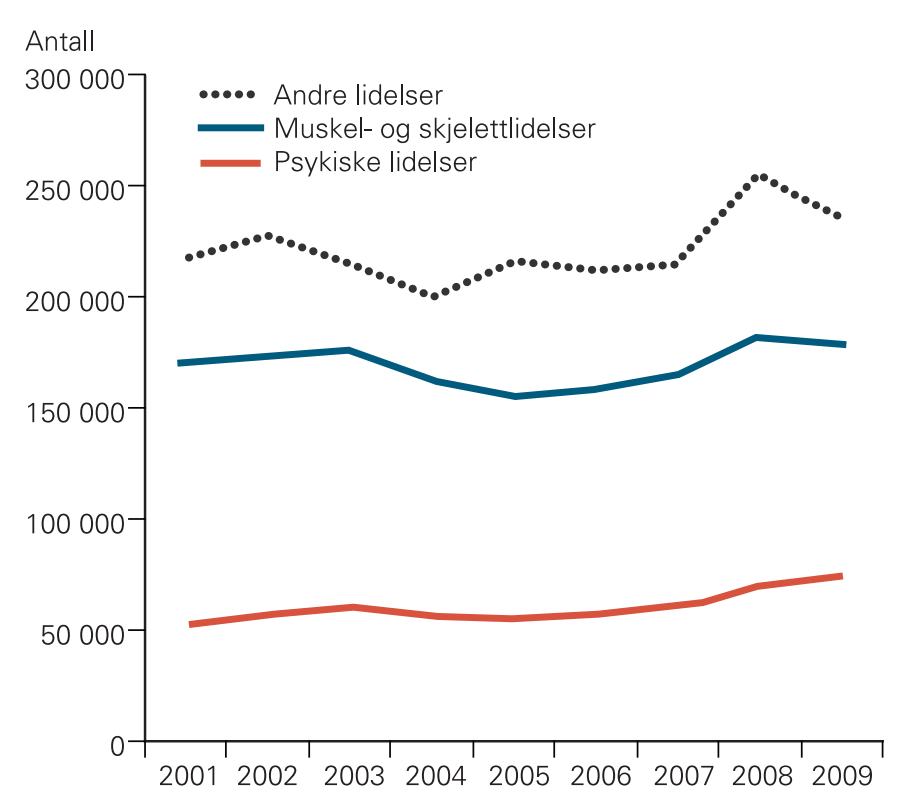

Figur 1 Antall sykefraværstilfeller i 2. kvartal 2001-2009 for muskel-og skjelettlidelser, psykiske lidelser og andre lidelser. Data fra NAV (5) lav sosioøkonomisk status og kroniske muskelsmerter (11, 13). Fysisk aktivitet kan forebygge kronifisering og konsekvenser av muskel- og skjelettsmerter (9).

Forekomsten av denne typen lidelser holder seg stabil i befolkningen over tid. I levekårsundersøkelsen i 1998 var det $25 \%$ som oppga å ha sykdom i muskel- og skjelettsystemet, mens tilsvarende tall for 2002 og
2005 var henholdsvis $23 \%$ og $24 \%$ (14). En slik stabil forekomst er også rapportert fra andre studier av den generelle befolkning i Norge $(7,15)$.

Tradisjonelt har mye av forskning og behandling av muskel- og skjelettplager, konsentrert seg om lokaliserte plager og spesifikke diagnoser. Men i HUSK fant man at blant dem som hadde kroniske muskel- og skjelett-

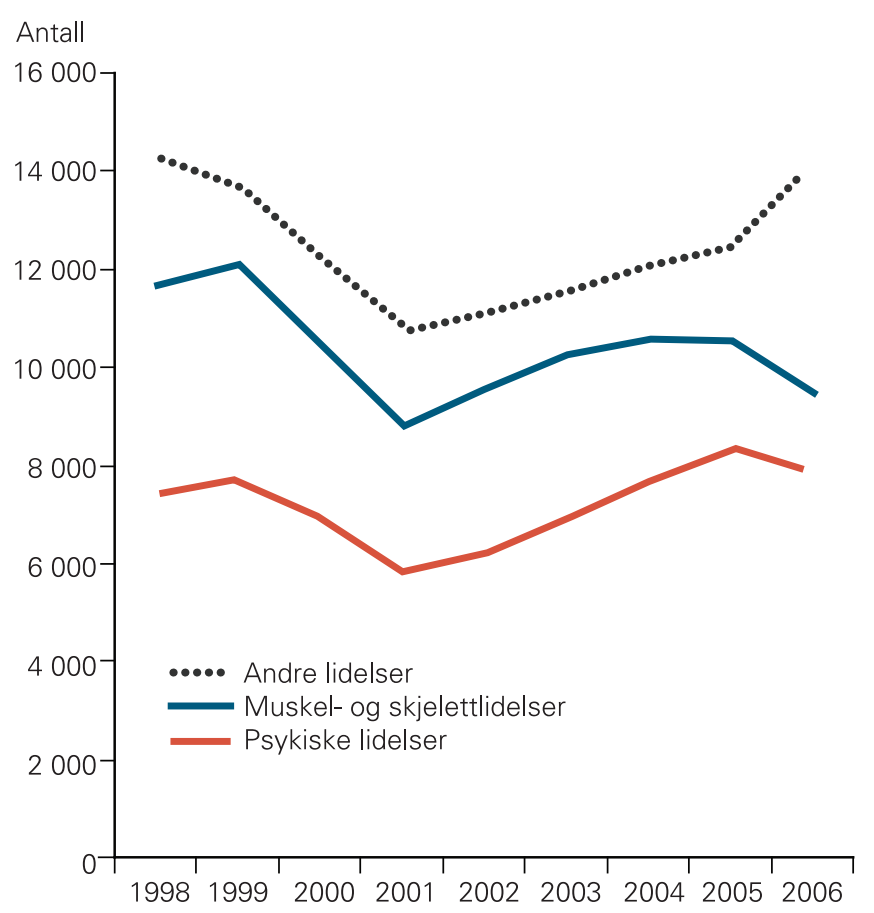

Figur 2 Antall nye tilfeller av uføreytelse 1998-2006 for muskel- og skjelettlidelser, psykiske lidelser og andre lidelser. Data fra NAV (6) plager, var det vanlig å rapportere plager fra tre eller flere kroppsdeler (10). Undersøkelser av befolkningen i Ullensaker over en 14-årsperiode har også vist at bare $11 \%$ av befolkningen hadde muskel og -skjelettsmerter fra ett område i løpet av det siste året, mens hele $39 \%$ hadde smerter fra fem områder eller flere (16). Særlig kvinner, personer med lav utdanning og personer med dårlig generell helse opplevde å ha smerter fra mange områder (16). Undersøkelsen viste videre at det var en klar og lineær sammenheng mellom økende antall smerteområder og nedsatt funksjon, og antall smerteområder predikerte uføretrygd 14 år senere $(17,18)$. I HUSK fant man at utbredte kroniske muskelog skjelettsmerter ser ut til å være en uavhengig prediktor for fremtidig høyt sykefravær (11).

Muskel- og skjelettlidelsene er den hyppigste årsaken til en rekke trygdeytelser. De svarte for $36 \%$ av sykefraværstilfellene i 2. kvartal 2009 (5) og 30\% av alle nye tilfeller av uføreytelser i 2006 (6). Den nest største diagnosegruppen, psykiske lidelser, ga opphav til $15 \%$ av sykefraværstilfellene og $25 \%$ av nye uføreytelser. Fra 2001 økte sykefraværet markant for psykiske lidelser og andre lidelser, mens sykefraværet på grunn av muskel- og skjelettlidelser stort sett var uforandret (fig 1). Antallet nye tilfeller av uføreytelser på grunn av muskel- og skjelettlidelser viste en absolutt nedgang $\mathrm{i}$ perioden 1998-2006 (fig 2). Den muskelog skjelettlidelsesbaserte andel av disse viktige trygdeytelsene har $\mathrm{i}$ de siste ti årene vist en fallende tendens.

\section{Revmatiske sykdommer}

Prevalensen av revmatoid artritt i befolkningen ligger på omkring $0,5 \%$, og det er flere kvinner enn menn som har denne sykdommen (19). Den årlige insidensen er funnet å være ca. 25 per 100000 innbyggere i Oslo (20) og 29 per 100000 innbyggere i Troms (21). Forekomsten av Bekhterevs sykdom er antatt å ligge på mellom $0,1 \%$ og ca. $1 \%$, og det er flest menn som rammes (22). I en studie av befolkningen i Tromsø, fant man en punktprevalens på $0,4 \%$ (23). Den estimerte gjennomsnittlige årlige insidensen i perioden 1960-93 ble beregnet til 7,3 per 100000 innbyggere.

Revmatiske sykdommer svarte for $1 \%$ av sykepengetilfellene i 2008 og for $2 \%$ av nye uføreytelser i 2006 (24). Det er tegn til at leddgikt er blitt en mildere sykdom de siste tiårene, muligens på grunn av nye sykdomsmodifiserende medikamenter (25). Men i en studie av norske arbeidstakere som var sykmeldt for muskel- og skjelettlidelser i mer enn åtte uker, var denne diagnosen en av høyrisikodiagnosene for å være mottaker av en uføreytelse fem år senere (26).

\section{Degenerative sykdommer}

Forekomsten av selvrapportert diagnostisert artrose i Ullensaker-undersøkelsen var $12,8 \%$ (3). Hofteartrose ble rapportert av 
$5,5 \%$, artrose i kne av 7,1 \% og håndartrose av $4,3 \%$ (3). I Norge regner man med at 96 000-225 000 kvinner lider av osteoporose (27), og insidensen av osteoporoserelaterte brudd i Norge er den høyeste i verden (28). Artrose var bakgrunnen for $5 \%$ av alle nye uføreytelser i 2006 (24).

\section{Fibromyalgi}

Det er omdiskutert hvorvidt fibromyalgi er et klart avgrenset syndrom eller del av generaliserte muskelsmerter (29). Sammenliknet med andre land er forekomsten av fibromyalgi i Norge forholdsvis høy. I en undersøkelse av nærmere 93000 innbyggere i Nord-Trøndelag fant man at prevalensen var på 3,2\%. Blant kvinner var prevalensen på ca. $5 \%$ og blant menn ca. $1 \%$ (30), mens det $i$ en undersøkelse av kvinner i Arendal ble rapportert om en prevalens på 10,5\% (31). Av voksne fibromyalgipasienter er ca. $90 \%$ kvinner (32), og de fleste pasientene er i 40-50-årsalderen. Fibromyalgi førte til $5,4 \%$ av alle nye uføreytelser i 2006 (24).

\section{Rygglidelser}

Ryggsmerter er svært vanlig i befolkningen, og det er antatt at $60-80 \%$ vil erfare ryggsmerter i løpet av livet (33). Prevalens av isjias med nerverotssmerter angis til å ligge på $1-5 \%(33,34)$. For $80-90 \%$ av akutte korsryggsplager kan man ikke si noe sikkert om hvorfor smerten oppstår. I befolkningsundersøkelsen i Ullensaker i 2004, rapporterte $34 \%$ å ha opplevd korsryggssmerter og $18 \%$ smerter i øvre rygg i løpet av siste uke (17). I en undersøkelse av et representativt utvalg av yrkesaktive i Norge i 2003, fant man at $47 \%$ hadde hatt ryggplager siste måned, mens tilsvarende tall for 1996 var $46 \%$ (7). Hele $58 \%$ av norske ungdomsskoleelever i 8. og 9. klasse rapporterte å ha hatt ryggsmerter i løpet av siste år, og 32 \% rapporterte ryggsmerter i mer enn sju dager siste år (35). Av muskel- og skjelettlidelser er det rygglidelser som er den dominerende årsaken både til sykefravær og uføreytelser (24).

\section{Nakkelidelser}

Smerter og plager i nakken eller cervikaldelen av ryggsøylen kan være vanskelig å avgrense fra muskulære og andre plager i øvre rygg, nakke og skuldre. I en undersøkelse av et utvalg av yrkesaktive i den norske befolkningen i 2003, var det $33 \%$ som rapporterte nakkeplager i en eller annen grad i løpet av siste måned (7). I Ullensaker-undersøkelsen 2004 var det $36 \%$ som rapporterte å ha opplevd nakkesmerter siste uke, $43 \%$ av kvinner og $27 \%$ av menn (17). Ettårsprevalens av nakkeplager i befolkningen i Ullensaker er tidligere rapportert til å være $48 \%$ (36). Man vet ikke så mye om forekomsten av kroniske nakkesmerter i befolkningen, men $i$ en norsk studie hadde ca. $14 \%$ hatt kroniske plager som varte i mer enn seks måneder (37). Nakkelidelser er en vanlig årsak til både sykefravær og uføreytelser (24).
En nakkelidelse som har fått mye oppmerksomhet er nakkeslengskade. Det er omtrent 2000 nye tilfeller av nakkeslengskade ( grad I og II) i Norge hvert år. Hos 3-5\% av personer som har vært utsatt for en påkjørsel som gir nakkesleng, vil det utvikle seg symptomer på en nakkeslengskade innen tre dager. Et mindretall av disse igjen vil utvikle kroniske plager (38). I en oppfølgingsstudie av personer som rapporterte personskade etter bilulykke til et norsk forsikringsselskap, rapporterte ca. $70 \%$ nakkesmerter etter ulykken og ca. $14 \%$ utviklet kroniske nakkesmerter (39).

\section{Skulderplager}

Skulderplager var sammen med nakke og ryggplager den hyppigst rapporterte plagen i Ullensaker-undersøkelsen i 2004, og $34 \%$ hadde opplevd skulderplager siste uke (17). Årsprevalensen for skulderplager i Ullensaker er tidligere funnet å være $47 \%$ (36).

\section{Bekkensmerter}

Hele $46 \%$ av gravide kvinner opplever bekkensmerter i løpet av svangerskapet (40). For de fleste vil disse plagene gå over av seg selv i løpet av 1-3 måneder etter fødselen, men for noen blir plagene langvarige og alvorlige (41). Prevalensen av kroniske bekkensmerter i befolkningen er ukjent, men ca. $40 \%$ av dem som oppsøker allmennlege eller gynekolog for underlivsplager har kroniske bekkensmerter (42).

\section{Diskusjon}

Muskel- og skjelettlidelser er utbredt $i$ befolkningen og er fortsatt en viktig årsak til trygdeytelser. I de siste årene har antallet personer med sykefravær på grunn av muskel- og skjelettdiagnoser vært omtrent stabilt, mens for uføreytelser har antallet nye tilfeller med muskel- og skjelettlidelser vist både en absolutt og en relativ nedgang. Det er imidlertid lite som tyder på at dette skyldes en reell nedgang i forekomst av muskelog skjelettplager $(7,14)$.

Den generelle økningen i ytelsene har vært forårsaket av andre lidelser, først og fremst psykiske lidelser. Dette bekrefter fortsettelsen på en trend som også er rapportert før (43). Det er tidligere vist at det er liten overensstemmelse mellom forekomst av plager i den generelle befolkning og forekomst av tilsvarende diagnoser $(7,44)$. Samtidig vet man at pasienter med langvarige muskel- og skjelettplager ofte også opplever psykiske plager som depresjon $(45,46)$. Det kan derfor være rimelig å diskutere om endringene skyldes en endret bruk av psykiatriske diagnoser på pasienter som tidligere ville fått en muskel- og skjelettdiagnose, etter hvert som det er blitt mer åpenhet $\mathrm{i}$ samfunnet omkring psykiske problemer.

I Ullensaker-undersøkelsen fant man at de aller fleste som rapporterer muskel- og skjelettsmerter, rapporterer smerter fra flere områder (17). Tilsvarende funn er gjort i en stu- die av norske ryggpasienter, der majoriteten av pasientene også hadde en rekke andre plager (46). For pasienter med smerter fra mange deler av muskel- og skjelettsystemet samt en rekke andre plager, kan det være flere mulige diagnoser å velge mellom, og det kan bli litt tilfeldig hvilken diagnose de får. Hvilken diagnose som stilles kan avhenge av hvilken plage pasienten eller legen opplever som mest funksjonsnedsettende, hvilken type spesialist pasientene går til, eller hva som er mest akseptert i samfunnet. Det ser uansett ut som det ikke er lokalisering av smerter og plager som er det viktigste når det gjelder å påvirke funksjon, sykmelding og uføreytelser for personer med muskel- og skjelettplager, men antall smerteområder $(11,17,18)$.

Selv om det er visse endringer i diagnosebruken, er det fortsatt slik at muskel- og skjelettlidelser plager flest og koster mest (4). Samtidig vet man at blant leger i Norge befinner disse lidelsene seg nederst på prestisjehierarkiet for ulike sykdommer (47). Kunnskapsgrunnlaget for å forstå årsaker og iverksette forebyggende og behandlingsrettede tiltak for muskel - og skjelettlidelser er fortsatt beskjedent.

Oppgitte interessekonflikter: Ingen

\section{Litteratur}

1. Steinsbekk A, Adams J, Sibbritt D et al. The profiles of adults who consult alternative health practitioners and/or general practitioners. Scand J Prim Health Care 2007; 25: 86-92.

2. Dagfinrud H, Kjeken I, Mowinckel P et al. Impact of functional impairment in ankylosing spondylitis impairment, activity limitation, and participation restrictions. J Rheumatol 2005; 32: 516-23.

3. Grotle M, Hagen KB, Natvig B et al. Prevalence and burden of osteoarthritis: results from a population survey in Norway. J Rheumatol 2008; 35: 677-84.

4. Ihlebæk C, Lærum E. Plager flest - koster mest, muskel-skjelettlidelser i Norge. Rapport nr. 1/2004. Oslo: Nasjonalt Ryggnettverk - Formidlingsenheten, 2004

5. NAV. Sykefraværstilfeller 2 kv 2001-2009 http://nav.no/212995.cms. (19.2.2010).

6. NAV. Diagnoser uføreytelser. www.nav.no/805380444.cms (13.1.2010).

7. Ihlebaek C, Brage S, Eriksen HR. Health complaints and sickness absence in Norway. 1996-2003. Occup Med (Lond) 2007; 57: 43-9.

8. Hagen K, Svebak S, Zwart JA. Incidence of musculoskeletal complaints in a large adult Norwegian county population. The HUNT Study. Spine (Phila Pa 1976) 2006; 31: 2146-50

9. Holth HS, Werpen HK, Zwart JA et al. Physical inactivity is associated with chronic musculoskeletal complaints 11 years later: results from the Nord-Trøndelag Health Study. BMC Musculoskelet Disord 2008; 9: 159

10. Sirnes E, Sødal E, Nurk E et al. Forekomst av mus kel- og skjelettplager i Hordaland. Tidsskr Nor Lægeforen 2003; 123: 2855-9.

11. Andersen I, Frydenberg H, Mæland JG. Muskelog skjelettplager og fremtidig sykefravær. Tidsskr Nor Legeforen 2009; 129: 1210-3.

12. Rustøen T, Wahl AK, Hanestad BR et al. Age and the experience of chronic pain: differences in health and quality of life among younger, middleaged, and older adults. Clin J Pain 2005; 21 513-23.

13. Hagen K, Zwart JA, Svebak S et al. Low socioeconomic status is associated with chronic musculoskeletal complaints among 46,901 adults in Norway. Scand J Public Health 2005; 33: 268-75. 
14. Statistisk sentralbyrå. Levekårsundersøkelsene 1998-2005. www.ssb.no/emner/03/01/ helseforhold/tab/tabeller.html (19.2.2010)

15. Kamaleri Y, Natvig B, Ihlebaek CM et al. Change in the number of musculoskeletal pain sites: A 14-year prospective study. Pain 2009; 141 : 25-30.

16. Kamaleri Y, Natvig B, Ihlebaek CM et al. Number of pain sites is associated with demographic, lifestyle, and health-related factors in the general population. Eur J Pain 2008; 12: 742-8.

17. Kamaleri Y, Natvig B, Ihlebaek CM et al. Localized or widespread musculoskeletal pain: does it matter? Pain 2008; 138: 41-6.

18. Kamaleri Y, Natvig B, Ihlebaek CM et al. Does the number of musculoskeletal pain sites predict work disability? A 14-year prospective study. Eur J Pain 2009; 13: 426-30.

19. Kvien TK, Uhlig T, Ødegård S et al. Epidemiological aspects of rheumatoid arthritis: the sex ratio. Ann N Y Acad Sci 2006; 1069: 212-22

20. Uhlig T. Revmatoid artritt. Tidsskr Nor Lægeforen 2001: 121: 86.

21. Riise T, Jacobsen BK, Gran JT. Incidence and prevalence of rheumatoid arthritis in the county of Troms, northern Norway. J Rheumatol 2000; 27: 1386-9.

22. Dagfinrud H, Heiberg MS, Bakland G et al. Bekhterevs sykdom - en konsensus om diagnostikk og behandling. Tidsskr Nor Lægeforen 2007; 127: 3209-12.

23. Bakland G, Nossent HC, Gran JT. Incidence and prevalence of ankylosing spondylitis in Northern Norway. Arthritis Rheum 2005; 53: $850-5$.

24. Brage S, Ihlebæk C, Natvig B et al. Muskel-og skjelettlidelser som årsak til sykefravær og uføreytelser. Tidsskr Nor Legeforen 2010; 130: $0000-00$

25. Uhlig T, Heiberg T, Mowinckel P et al. Rheumatoid arthritis is milder in the new millennium: health status in patients with rheumatoid arthritis 1994-2004. Ann Rheum Dis 2008; 67: 1710-5.
26. Gjesdal S, Bratberg E, Maeland JG. Musculoskeletal impairments in the Norwegian working population: the prognostic role of diagnoses and socioeconomic status: a prospective study of sickness absence and transition to disability pension. Spine (Phila Pa 1976) 2009; 34: 1519-25.

27. Nasjonalt folkehelseinstitutt. Tema: Beinskjørhet og brudd - osteoporose. www.fhi.no/ eway/default.aspx?pid=233\&trg=MainArea 5661\&MainArea_5661 $=5565: 0: 15,3302: 1: 0: 0: 0: 0$. (19.2.2010).

28. Lofthus CM, Osnes EK, Falch JA et al. Epidemiology of hip fractures in Oslo, Norway. Bone 2001: 29: 413-8.

29. Gran JT. The epidemiology of chronic generalized musculoskeletal pain. Best Pract Res Clin Rheumatol 2003; 17: 547-61.

30. Kurtze N, Svebak S. Fatigue and patterns of pain in fibromyalgia: correlations with anxiety, depression and co-morbidity in a female county sample. Br J Med Psychol 2001; 74: 523-37.

31. Forseth $K \emptyset$. Fibromyalgi - forekomst og risikofaktorer. Tidsskr Nor Lægeforen 2000; 120: 1885

32. Wigers SH. Fibromyalgi - en oppdatering. Tidsskr Nor Lægeforen 2002; 122: 1300-4.

33. Lærum E. Nasjonale kliniske retningslinjer. Korsryggsmerter - med og uten nerverotaffeksjon. Oslo: Formi, 2007.

34. Grøvle L, Haugen AJ, Keller A et al. The bothersomeness of sciatica: patients' self-report of paresthesia, weakness and leg pain. Eur Spine J 2010; 19: 263-9.

35. Sjølie AN. Persistence and change in nonspecific low back pain among adolescents: a 3-year prospective study. Spine (Phila Pa 1976) 2004; 29 : 2452-7.

36. Natvig B, Nessiøy I, Bruusgaard D et al. Musculoskeletal symptoms in a local community. Eur J Gen Pract 1995; 1: 25-8.

37. Bovim G, Schrader H, Sand T. Neck pain in the general population. Spine (Phila Pa 1976) 1994; 19: 1307-9.
38. Rø M, Borchgrevink G, Dæhlie B. Nakkeslengskade. Diagnostikk og evaluering. Metodevurdering basert på egen litteraturgransking. SMM-rapport nr. 5/2000. Oslo: SINTEF, 2000.

39. Pape E, Brox JI, Hagen KB et al. Prognostic factors for chronic neck pain in persons with minor or moderate injuries in traffic accidents. Accid Anal Prev 2007; 39: 135-46.

40. Robinson HS, Eskild A, Heiberg E et al. Pelvic girdle pain in pregnancy: the impact on function. Acta Obstet Gynecol Scand 2006; 85: $160-4$

41. Stuge B, Laerum E, Kirkesola $G$ et al. The efficacy of a treatment program focusing on specific stabilizing exercises for pelvic girdle pain after pregnancy: a randomized controlled trial. Spine (Phila Pa 1976) 2004; 29: $351-9$

42. Kirste U, Haugstad GK, Leganger S. Kroniske bekkensmerter hos kvinner. Tidsskr Nor Lægeforen 2002; 122: 1223-7.

43. Rikstrygdeverket. Diagnoser og sykefravær 1994-1999. Rapport nr. 4/2000. Oslo: Rikstrygdeverket, 2000

44. Wikman A, Marklund S, Alexanderson K. Illness, disease, and sickness absence: an empirical test of differences between concepts of ill health. J Epidemiol Community Health 2005; 59: 450-4.

45. Brage S, Sandanger I, Nygård JF. Emotional distress as a predictor for low back disability: a prospective 12-year population-based study. Spine (Phila Pa 1976) 2007; 32: 269-74

46. Hagen EM, Svensen E, Eriksen HR et al. Comorbid subjective health complaints in low back pain. Spine (Phila Pa 1976) 2006; 31: 1491-5.

47. Album D, Westin S. Do diseases have a prestige hierarchy? A survey among physicians and medical students. Soc Sci Med 2008; 66: 182-8.

Manuskriptet ble mottatt 23.6. 2009 og godkjent 1.7. 2010. Medisinsk redaktør Anne Kveim Lie. 